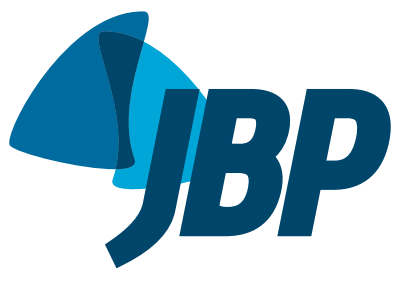

\title{
Knowledge and perceptions of tuberculosis transmission and prevention among physicians and nurses in three Brazilian capitals with high incidence of tuberculosis
}

\author{
Jonas Ramos ${ }^{1, a}$, Maria F Wakoff-Pereira',b, Marcelo Cordeiro-Santos ${ }^{2,3, c}$, \\ Maria de Fátima Militão de Albuquerque ${ }^{4, \mathrm{~d}}$, Philip $\mathrm{C} \mathrm{Hill}^{5, \mathrm{e}}$, Dick Menzies ${ }^{6, \mathrm{f}}$, \\ Anete Trajman, ${ }^{6,7, \mathrm{~g}}$
}

\section{TO THE EDITOR:}

The Sustainable Development Goals ${ }^{(1)}$ and the End TB Strategy ${ }^{(2)}$ have set targets for tuberculosis elimination by 2050 . Recent projections have shown that, in order to achieve interim targets for 2030 , prevention through detection and treatment of latent tuberculosis infection (LTBI) is essential. (3) Major target groups for LTBI treatment include immunosuppressed patients ${ }^{(4)}$ and close contacts of index cases, ${ }^{(5)}$ because they are at high risk of progression to active tuberculosis. However, less than $5 \%$ of infected contacts are diagnosed and treated to prevent tuberculosis. ${ }^{(6)}$ The reasons for that are not well understood.

In Brazil, major losses occur in the early steps of the cascade of care for LTBI: only $43 \%$ of all close contacts are identified, and, of those, only $3 \%$ are started on treatment. (7) Perceptions on the part of index patients and contacts do not seem to be at the root of this problem. Index patients fear that contacts will become ill and do tell them that they have tuberculosis. Contacts also fear TB and declare that they would take treatment to prevent it if prescribed. ${ }^{(7)}$ In the present study, we used a knowledge, attitudes, and practices survey ${ }^{(8)}$ in order to explore the perspectives of primary care physicians and nurses regarding TB transmission and prevention at 12 primary health care clinics in the cities of Recife, Manaus, and Rio de Janeiro, where the incidence of tuberculosis in Brazil is highest. ${ }^{(9)}$ The present study is part of a larger study aimed at implementing solutions to the aforementioned problem (ClinicalTrials.gov identifier: NCT00931736 [http://www.clinicaltrials.gov/]). The aforementioned clinics are the same as those where we interviewed index patients and contacts. ${ }^{(7)}$

Between January of 2015 and July of 2016, a semistructured questionnaire consisting of open-ended questions on tuberculosis transmission and prevention was administered by trained interviewers to the physicians and nurses who consented to participate in the study. The questionnaire used in the present study is a shortened version of a questionnaire that has previously been used in Indonesia, ${ }^{(10)}$ having previously been translated to Portuguese and adapted for use in Brazil by our research group. A pilot study including 10 health professionals allowed us to make final refinements to the instrument. Participant answers were divided into predefined categories, and the categories were further classified as satisfactory (not necessarily $100 \%$ correct) if the answers included categories that were considered "compulsory" and no categories that were considered "unacceptable". For instance, prevention of tuberculosis disease in infected contacts was considered satisfactory if taking medicine, isoniazid, or any effective prophylactic regimen was mentioned and no religious belief was mentioned. A panel of three experts determined whether or not answers were satisfactory by judging whether or not slightly incorrect answers had a negative impact on contact management. The answers were compared between physicians and nurses, between health professionals with and without previous training in tuberculosis, and among the three cities involved in the study.

The study was approved by the local research ethics committees (Rio de Janeiro, Protocol no. CAAE 762,361; Manaus, Protocol no. CAAE 998,112; and Recife, Protocol no. CAAE 1,097,557). All participants gave written informed consent, and their answers remained anonymous.

Interviewers approached 55 physicians and 46 nurses, all of whom agreed to participate. Of the sample as a whole, $58 \%$ reported having recently received formal training in tuberculosis. Of those, $57 \%$ had received training in tuberculosis prevention and LTBI management. Despite having received formal training, less than $50 \%$ of the participants answered 7 of the 16 questions satisfactorily (Table 1). Knowledge gaps included prevention of LTBI among contacts $(51 \%)$, prevention of progression to disease after infection (32\%), LTBI diagnosis (43\%), indications for LTBI treatment (62\%), minimum duration of isoniazid treatment (44\%), isoniazid dose (84\%), and management of adverse events (57\%). Of the sample

\footnotetext{
1. Programa de Pós-Graduação em Clínica Médica, Universidade Federal do Rio de Janeiro, Rio de Janeiro (RJ) Brasil.

2. Fundação de Medicina Tropical do Amazonas Dr. Heitor Vieira Dourado, Manaus (AM) Brasil.

3. Universidade do Estado do Amazonas, Manaus (AM) Brasil.

4. Centro de Pesquisa Aggeu Magalhães, Fundação Oswaldo Cruz, Recife (PE) Brasil

5. Centre for International Health, University of Otago, Dunedin, New Zealand.

6. Respiratory Epidemiology \& Clinical Research Unit - RECRU - McGill University, Montreal, Canada.

7. Instituto de Medicina Social, Universidade do Estado do Rio de Janeiro, Rio de Janeiro (RJ) Brasil.

a. (iD) http://orcid.org/0000-0001-9034-3311; b. ID http://orcid.org/0000-0003-4638-2166; c. (iD http://orcid.org/0000-0002-7140-7145

d. (iD) http://orcid.org/0000-0002-4999-4160; e. (iD) http://orcid.org/0000-0002-7006-0549; f. (iD) http://orcid.org/0000-0003-1601-4514;

g. (iD http://orcid.org/0000-0002-4000-4984
} 
Table 1. Proportions of satisfactory answers to questions in a knowledge, attitudes, and practices survey among 55 physicians and 46 nurses in three cities in Brazil with high incidence of tuberculosis.

$\begin{array}{cc}\text { Question } & \begin{array}{c}\text { Proportion of } \\ \text { satisfactory answers }\end{array}\end{array}$

Knowledge

\begin{tabular}{|c|c|}
\hline How is a contact of an index patient with TB prevented from becoming infected? & $50 \%$ \\
\hline How can a person with LTBI be prevented from becoming ill? & $68 \%$ \\
\hline What tests are recommended for an asymptomatic contact? & $57 \%$ \\
\hline What tests are recommended for a contact with cough? & $48 \%$ \\
\hline How do you determine that a TB contact has been infected (with LTBI)? & $46 \%$ \\
\hline $\begin{array}{l}\text { According to the recommendations of the Brazilian National Tuberculosis Control Program, } \\
\text { what household contacts should receive treatment for LTBI? }\end{array}$ & $38 \%$ \\
\hline What is the minimum duration of LTBI treatment with isoniazid to prevent TB disease? & $56 \%$ \\
\hline What is the optimal duration of LTBI treatment with isoniazid to prevent TB disease? & $7 \%$ \\
\hline What is the recommended dose of isoniazid for the treatment of LTBI in children? & $16 \%$ \\
\hline What is the daily dose of isoniazid for the treatment of LTBI in adults? & $7 \%$ \\
\hline What are the most common side effects of isoniazid? & $82 \%$ \\
\hline What household contacts should be vaccinated with BCG? & $15 \%$ \\
\hline $\begin{array}{l}\text { What do you do if an adult taking isoniazid for LTBI treatment has nausea and loss of } \\
\text { appetite? }\end{array}$ & $67 \%$ \\
\hline $\begin{array}{l}\text { What do you do if a child taking isoniazid for LTBI treatment has nausea and loss of } \\
\text { appetite? }\end{array}$ & $48 \%$ \\
\hline What do you do if an adult taking isoniazid for LTBI treatment has jaundice? & $69 \%$ \\
\hline What do you do if a child taking isoniazid for LTBI treatment has jaundice? & $65 \%$ \\
\hline \multicolumn{2}{|l|}{ Attitudes } \\
\hline $\begin{array}{l}\text { Do you think it is important for a child who lives with a patient with active TB to be } \\
\text { screened for active TB? }\end{array}$ & $73 \%$ \\
\hline $\begin{array}{l}\text { Do you think it is important for a child who lives with a patient with active TB to be } \\
\text { screened for LTBI? }\end{array}$ & $54 \%$ \\
\hline $\begin{array}{l}\text { Do you think it is important for an adult who lives with a patient with active TB to be } \\
\text { screened for active TB? }\end{array}$ & $63 \%$ \\
\hline $\begin{array}{l}\text { Do you think it is important for an adult who lives with a patient with active TB to be } \\
\text { screened for LTBI? }\end{array}$ & $51 \%$ \\
\hline $\begin{array}{l}\text { Do you think that this health care clinic should be responsible for investigating adults and } \\
\text { children living with a patient with active TB? }\end{array}$ & $78 \%$ \\
\hline $\begin{array}{l}\text { Sometimes parents/legal guardians do not bring their child contacts to the clinic for LTBI/ } \\
\text { TB investigation. What do you think are the main reasons for that? }\end{array}$ & $92 \%$ \\
\hline $\begin{array}{l}\text { Sometimes adult contacts do not come to the clinic to be investigated. What do you think } \\
\text { are the main reasons for that? }\end{array}$ & $93 \%$ \\
\hline In this clinic, what are the difficulties in evaluating a child living with a patient with TB? & $71 \%$ \\
\hline In this clinic, what are the difficulties in evaluating an adult living with a patient with TB? & $51 \%$ \\
\hline
\end{tabular}

TB: tuberculosis; and LTBI: latent tuberculosis infection.

as a whole, $46 \%$ stated that they did not think that it was important to screen child contacts for tuberculosis and LTBI and $49 \%$ stated that they did not think that it was important to screen adult contacts for tuberculosis and LTBI, attitudes that stand in contrast with the Brazilian National Guidelines for Tuberculosis Control.

Although physicians had better knowledge of management of adverse events than did nurses, there were no other significant differences in knowledge or perceptions between physicians and nurses (with or without previous training). With regard to the differences among the three cities, the proportions of satisfactory answers regarding tuberculosis transmission and investigation of contacts were lowest in Manaus, whereas the proportions of satisfactory answers regarding duration of isoniazid treatment and isoniazid dose were lowest in
Rio de Janeiro. In Recife, none of the participants stated that it is important to screen child or adult contacts for LTBI (data on answers by professional category, training status, and city are not shown but are available upon request to the corresponding author, as is the questionnaire used in the present study).

In conclusion, there are major gaps in knowledge of and attitudes toward tuberculosis contact management among primary health care physicians and nurses, despite previous tuberculosis training. Inclusion of tuberculosis prevention in training sessions and motivation of health care workers are needed in order to overcome bottlenecks in LTBI treatment in Brazil. We propose standardized training as a solution to issues of LTBI treatment of close contacts of tuberculosis patients, as recommended by the Brazilian National Guidelines 
for Tuberculosis Control. We believe that this approach can aid in determining priorities for LTBI management in settings in which the cascade of care of tuberculosis contacts is an issue for tuberculosis control.

\section{REFERENCES}

1. United Nations [homepage on the Internet]. New York City: United Nations; [cited 2017 Aug]. Sustainable Development Goals; [about 2 screens]. Available from: http://www.un.org/ sustainabledevelopment/sustainable-development-goals/

2. World Health Organization [homepage on the Internet]. Geneva: World Health Organization [cited 2017 Aug 25]. WHO End TB Strategy-Global strategy and targets for tuberculosis prevention, care and control after 2015; [about 2 screens]. Available from: http:// www.who.int/tb/post2015_strategy/en/

3. Dye C, Glaziou P, Floyd K, Raviglione M. Prospects for tuberculosis elimination. Annu Rev Public Health. 2013;34:271-86. https://doi org/10.1146/annurev-publhealth-031912-114431

4. World Health Organization [homepage on the Internet]. Geneva: World Health Organization [cited 2017 Aug 25]. Scaling up the Three I's for TB/HIV; [about 1 screen]. Available from: http://www.who.int/ hiv/topics/tb/3is/en/

5. World Health Organization [homepage on the Internet]. Geneva: World Health Organization [cited 2017 Aug 29]. Guidelines on the management of latent tuberculosis infection; [about 3 screens]. Available from: http://www.who.int/tb/publications/latenttuberculosis-infection/en/

6. Alsdurf H, Hill PC, Matteelli A, Getahun H, Menzies D. The cascade of care in diagnosis and treatment of latent tuberculosis infection: a systematic review and meta-analysis. Lancet Infect Dis. $\quad 2016 ; 16(11): 1269-1278 . \quad$ https://doi.org/10.1016/S14733099(16)30216-X

7. Salame FM, Ferreira MD, Belo MT, Teixeira EG, Cordeiro-Santos M, Ximenes RA, et al. Knowledge about tuberculosis transmission and prevention and perceptions of health service utilization among index cases and contacts in Brazil: Understanding losses in the latent tuberculosis cascade of care. PLoS One. 2017;12(9):e0184061. https://doi.org/10.1371/journal.pone.0184061

8. World Health Organization. Stop TB Partnership [homepage on the Internet]. Geneva: World Health Organization; [cited 2017 Aug 25]. Advocacy, communication and social mobilization for TB control: a guide to developing knowledge, attitude and practice surveys; 2008 [Adobe Acrobat document, 68p.]. Available from: http://apps.who.int/ iris/bitstream/10665/43790/1/9789241596176_eng.pdf

9. Brasil. Ministério da Saúde [homepage on the Internet]. Brasília: Ministério; [cited 2017 Aug 25]. Available from: http://portalsaude. saude.gov.br/

10. Rutherford ME, Ruslami R, Anselmo M, Alisjahbana B, Yuliant $\mathrm{N}$, Sampurno $\mathrm{H}$, et al. Management of children exposed to Mycobacterium tuberculosis: a public health evaluation in West Java, Indonesia. Bull World Health Organ. 2013;91(12):932-941A. https:// doi.org/10.2471/BLT.13.118414 